\title{
LA HUELGA DE I967 EN LA EsCUEla SuPERIOR DE AGRICULTURA HERMANOS ESCOBAR
}

\author{
ALICIA DE LOS RÍOS
}

\section{RESUMEN}

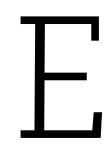

n el 2017 se cumplen cincuenta años de una huelga en la Escuela Superior de Agricultura Hermanos Escobar en Ciudad Juárez, Chihuahua. La movilización originó la creación de la Escuela de Agronomía de la Universidad Autónoma de Chihuahua; además, fue el antecedente organizativo nacional del movimiento estudiantil de 1968. Este texto reconstruye un fragmento histórico del tiempo reciente, a partir de la memoria de algunos actores. Entre recuerdos y fuentes documentales, se indagan tanto experiencias como expectativas de futuro de una generación que demandó educación y democracia.

Palabras clave: historia oral, huelgas estudiantiles, conmemoración

En la historia reciente de México se construye un calendario sobre movimientos sociales del pasado al que recurrentemente acudimos para explicar la radicalización política y militar de cientos de jóvenes en la década de los setenta. Comúnmente se invocan dos fechas emblemáticas: la primera es la irrupción del Grupo Popular Guerrillero (GPG) en Ciudad Madera el 23 de septiembre de 1965, cuyo cincuenta aniversario recién se conme- 
moró. ${ }^{1}$ La otra fecha multicitada es el movimiento estudiantil de 1968, el cual seguramente será objeto de rememoración y análisis mundial el próximo año.

Ambas fechas son un ejemplo útil para observar la homogeneidad sobre las ideas de insurrección y movilización estudiantil que prevalecen en nuestro imaginario social, aunque entre ambos existan diferencias de fondo y forma, incomprensibles para una mayoría no especialista en el tema. Alrededor de la década de 1960 persiste la representación de un proceso cultural, ideológico, económico y político único, donde ser revolucionario era similar a ser jipi. En sentido evolutivo, se piensa a las organizaciones políticas militares como herederas únicas de los movimientos sociales detenidos por la represión estatal.

Debido a ello, el concepto de movimiento estudiantil nos remite inmediatamente al período comprendido entre los últimos días de julio a los primeros de octubre de 1968 en la ciudad de México; un festejo democrático y alegre que desafió a las instituciones, abruptamente finalizado por un despliegue de violencia estatal inigualable, por lo menos en el resto del siglo XX, ${ }^{2}$ lo que popularmente explica la aparición de aproximadamente una treintena de organizaciones radicales de izquierda. Ese determinismo que sugiere la represión estatal como origen primordial de la insurgencia, obstruye las explicaciones sobre la rebelión en nuestro país,

1 El Grupo Popular Guerrillero (GPG) surge de las movilizaciones agraristas que se relacionaron con los profesores y estudiantes normalistas de principios de la década de los 1960 en Chihuahua. El GPG es un caso de radicalización política del movimiento popular previo, desconocido historiográficamente, siendo el asalto al cuartel Madera el capítulo más reconstruido y divulgado. En el contexto de la conmemoración del cincuenta aniversario, se presentaron dos textos novedosos sobre el movimiento campesino y normalista de los historiadores Aleida García Aguirre y Jesús Vargas Valdés, quienes centraron sus investigaciones en los procesos anteriores a la guerrilla.

2 Aunque en la década de los setenta se aplicaron estrategias contrainsurgentes para perseguir y aniquilar organizaciones opositoras con un mayor número de personas desaparecidas y ejecutadas, los crímenes tuvieron lugar en espacios confidenciales o inaccesibles como campos clandestinos o militares. En el caso del 2 de octubre, la cantidad de testigos sobrevivientes y las fuentes del fotoperiodismo, así como las oficiales que han sido desclasificadas, mostraron el despliegue público de las fuerzas armadas y policiacas del Estado mexicano. Creemos que el paradigma de la violencia en el imaginario social apenas ha sido equiparado con la guerra emprendida a partir del 2006. 
así como el abordaje autónomo de los movimientos estudiantiles. Al pretender recrear movilizaciones estudiantiles desde el norte, observé la construcción centralista de la memoria colectiva nacional, que deja fuera casi cualquier acontecimiento de provincia, la cual aparece como mero receptor de noticias. En contraste, se observa un ascendente abordaje del movimiento capitalino que modela un imaginario social a partir de imágenes épicas de México, Praga o París.

Para quienes investigamos organizaciones radicales de principio de la década de los 1970, irremediable y tautológicamente regresamos al movimiento de la ciudad de México de 1968 como un origen de la radicalidad. Curiosamente y de manera inversa, en Chihuahua la acción militar del GPG ha despertado un auge significativo en la academia y el periodismo a partir del ejercicio memorístico iniciado por sobrevivientes y familiares de los involucrados. Por ello nos preguntamos cuáles han sido los motivos de no abordar la historia reciente de los diversos movimientos estudiantiles en Chihuahua. ${ }^{3}$ ¿Acaso esa omisión es en sí misma una construcción discursiva y rectora sobre el pasado?

En un escenario actual adverso para la juventud, donde los espacios comunes de estudio, trabajo y diversión son privatizados, el posicionamiento del crimen organizado como una expectativa de futuro inmediato, además de una notable ausencia historiográfica sobre experiencias estudiantiles, me encontré con el esfuerzo conmemorativo de un colectivo de hombres agrónomos que participaron en la huelga de la Escuela Superior de Agricultura Hermanos Escobar (ESAHE) de mayo a julio de 1967. Constituidos como la Asociación Civil Rodolfo Posadas, se plantearon reconstruir el proceso en el que participaron. En diversas ocasiones fui convidada a escucharlos y posteriormente me propuse analizar sus experiencias, previas al estallido del movimiento es-

3 En el 2015 se publicó el libro de la M.H. Aleida García Aguirre, La revolución que llegaría, al que me atrevería a considerar como la única investigación que centra su interés en la experiencia de los jóvenes estudiantes que conformaron el movimiento normalista de principios de la década 1960 en Chihuahua, el cual generalmente se observó de reojo desde el movimiento armado del Grupo Popular Guerrillero (GPG). 
tudiantil de $1968 .{ }^{4}$ En las sesiones mis preguntas giraron acerca de orígenes y trayectorias de vida de mis interlocutores, así como de los agravios y deseos que los activaron política y colectivamente. ¿Quiénes eran esos jóvenes que prolongaron la huelga por sesenta y nueve días, extendiéndola a otras escuelas nacionales sin que militares u otras corporaciones intervinieran? ¿Qué relaciones modificó esa juventud que en 1967 demandó educación y soñó un futuro desde una geografía alejada del centro del país y próxima al liderazgo mundial capitalista? ¿Sus expectativas se modificaron al lograr resolver algunas demandas? ¿Qué agravios encontraron junto a otros estudiantes universitarios y cómo les hicieron frente? ¿Qué futuro colectivo alcanzaron?

Para responder la problemática de investigación, consideré necesario rastrear las expectativas de los jóvenes que, al advertir obstáculos para concluir sus estudios (y con ello un futuro laboral acorde a los nuevos conocimientos adquiridos teóricos y técnicos que los distinguirían de sus padres y abuelos), optaron por diversas formas de organización colectiva con el propósito de denunciar un abanico de agravios y exigir su solución. En la búsqueda de categorías sociales que permitieran el análisis de las entrevistas, me pareció oportuna la propuesta de Reinhart Koselleck sobre la experiencia y la expectativa. ${ }^{5}$ Espacio de experiencia es lo vivido y horizonte de expectativa es lo esperado por suceder. Dichas categorías brindan temporalidad a las acciones narradas. El presente es un puente que une al pasado vivido con el futuro que se deseó o anheló. Para los historiadores orales, la entrevista es el momento desde el cual se evocan los recuerdos del pasado (pretérito presente) así como de los futuros proyectados tiempo

4 Los días 23 y 24 de marzo del 2014 me reuní en la ciudad de San Luis Potosí con Pablo Martell, Eduardo Merrem, Ricardo Valenzuela y Jorge Posadas. Agradezco a Gabriel Villegas Osnaya por la grabación y fotografías de las entrevistas, así como a la Facultad de Filosofía y Letras de la UACH por financiar parte de esta investigación. A partir de la producción periodística, histórica y testimonial sobre el movimiento estudiantil de 1968, diversos autores plantean la huelga en la ESAHE como los antecedentes inmediatos de la gran huelga. Véase La democracia en la calle: crónica del movimiento estudiantil mexicano, de Gilberto Guevara Niebla. México, S XXI, Instituto de Investigaciones Sociales, UNAM, 1988, p. 34.

5 Reinhart Koselleck. Futuro pasado: para una semántica de los tiempos históricos. Madrid, Paidós Ibérica, 1993, pp. 333. 
atrás (futuro pasado), un presente desde el cual nuestros protagonistas recordaron sus experiencias y enunciaron frustraciones o triunfos en el ámbito político estudiantil. Identificar y narrar las experiencias previas individuales junto a la modelación de expectativas colectivas, resueltas o no, nos permite encontrar los tiempos largos detrás de cada experiencia, así como la intuición que provocó la elección de futuro entre los jóvenes. El análisis sobre experiencia y expectativa intenta abonar en la producción histórica social y conceptual; en este caso, con la interpretación de experiencias alrededor de movimientos estudiantiles y revolución comunista del pasado reciente en nuestro país.

En esa búsqueda de expectativas de los jóvenes huelguistas, con una delimitación espacial y temporal del año de 1967 en Ciudad Juárez, por sugerencia de un querido amigo, quien leyó un primer borrador, incorporé una modesta cronología del movimiento estudiantil en la ciudad de Chihuahua de 1968 a 1974, período en que se incorporaron los estudiantes huelguistas a la Universidad Autónoma de Chihuahua y participaron en sucesivas huelgas. ${ }^{6}$ La construcción de ese contexto al que arribaron en Chihuahua, tiene como fin observar la continuación o modificación de sus expectativas de futuro y la elección de estudio, trabajo o militancias por la democracia o la revolución, entre un abanico de opciones.

Me parece, como lo señalé al principio del texto, que la reconstrucción de los movimientos estudiantiles se diluye en procesos paralelos, ya sean populares o radicales. Como estrategia de análisis creo necesario ubicar las escuelas como los espacios históricos en los cuales se confrontaron las experiencias individuales y las utopías colectivas a través de la discusión y reflexión política,

6 La investigación de la huelga en la ESAHE forma parte de mi tesis doctoral en proceso, Ciudad Juárez: movimientos sociales y rebelión. Al sugerírseme mostrar la continuidad del activismo agrónomo en el movimiento estudiantil chihuahuense, los historiadores Marco de la Rosa y Lizeth Quintana consultaron y registraron el tema desde periódicos chihuahuenses en un período de 1967 a 1974, ya que en este año surgió un conflicto en la Escuela de Agronomía durante el cual una mayoría de estudiantes y profesores determinaron integrarse a la Escuela Nacional de Agricultura de Chapingo. Lo narrado acerca de las huelgas estudiantiles en Chihuahua es un primer acercamiento al tema, inconcluso, pendiente de una búsqueda exhaustiva documental y recopilación de entrevistas que permitan un análisis profundo del movimiento y las diversas luchas que se desprendieron de este. 
cultural, ideológica y académica. En la década de 1960 se cuestionó la legitimidad de las autoridades convencionales y se exigió la participación del alumnado en el proyecto educativo nacional. El investigador Antonio Gómez Nashiki caracteriza a la juventud movilizada alrededor de demandas estudiantiles como una generación que "responde a carencias institucionales: bajo presupuesto, deterioro de las condiciones físicas y materiales de trabajo, cuestionamiento a la legislación y tipo de gobierno universitario".? Por ejemplo, en octubre de 1966, en Michoacán surgió la movilización estudiantil en respuesta al embate del nuevo gobernador Arriaga contra el proyecto cardenista. Lo que inició como un conflicto por el alza de tarifas en el transporte, derivó en una huelga estudiantil y la demanda popular de desaparición de poderes. El ejército ocupó las instalaciones universitarias, desconociendo a la Junta de Gobierno Universitaria y al rector Gómez Reyes. Los estudiantes en su pliego petitorio exigieron la derogación del artículo 145 bis, ${ }^{8}$ la libertad de los presos políticos y el respeto a la autonomía universitaria, ${ }^{9}$ demandas que cobraron fuerza en 1968. Meses después en Sonora, en marzo de 1967, se presentó una situación similar propiciada por la elección priista a la gubernatura. Agentes policiacos ingresaron a las instalaciones de la Unison, violando la autonomía. El recién integrado Frente Estudiantil Anti Imposicionista (FEAI) y la Federación de Estudiantes Universitarios de Sonora (FEUS) estallaron la huelga, que alcanzó a la Escuela Normal, preparatorias, secundarias, primarias y al-

7 Antonio Gómez Nashiki. El movimiento estudiantil y la violencia institucional. La Universidad Michoacana de San Nicolás de Hidalgo, 1956-1966. Disponible en http:// www.comie.org.mx/documentos/rmie/v12/n035/pdf/N35D.pdf (revisado el 10 de febrero de 2016).

8 En 1941 se tipificó el delito de disolución social en el contexto mundial bélico, considerándose como "toda aquella forma hablada o escrita que realice propaganda política entre extranjeros o entre nacionales mexicanos [...] difundiendo ideas, programas o normas de acción, de cualquier gobierno extranjero, que afecten el reposo público o la soberanía del Estado Mexicano", es decir, que tendieran a "producir rebelión, tumulto, sedición o escándalos". Sin embargo tuvo un uso político como medida de control y represión en contra de opositores al régimen priista, como los líderes del movimiento ferrocarrilero.

9 Verónica Oikión. "El movimiento universitario de 1966 en Michoacán: una historia de confrontación política", páginas 387 - 402, en 154 años de movimientos estudiantiles en Iberoamérica. Coord. González Marín y Sánchez Sáenz. México. UNAM, IIB, Seminario Movimientos Estudiantiles. 2011. 
gunos colegios privados. En el mes de mayo la ciudad fue prácticamente tomada por el Ejército Mexicano, reanudándose hasta septiembre las clases en la universidad. ${ }^{10}$ Las movilizaciones en Michoacán y en Sonora surgieron en universidades públicas, gratuitas y autónomas, en contextos coyunturales. Por ello llama la atención que el 8 de mayo de 1967 en Ciudad Juárez, sin mediar conflicto local o estatal evidente, los estudiantes de la Escuela Superior de Agricultura Hermanos Escobar (ESAHE) estallaron la huelga con un pliego petitorio cuyo propósito principal era la federalización de la institución, privada hasta entonces.

En un esfuerzo de reconstruir una experiencia que posteriormente sea comparable con otras movilizaciones estudiantiles contemporáneas, describo someramente algunas formas en que los estudiantes plantearon las demandas de gratuidad y democratización de la educación a través de procesos de politización colectiva, ya fueran sociedades de alumnos, asambleas, comités de huelga, coordinadoras estudiantiles e incluso consejos resolutivos, técnicos o universitarios, así como el surgimiento de redes estudiantiles y alianzas populares. ${ }^{11}$ Asimismo, pensé preciso enunciar y caracterizar algunas autoridades responsables de la recepción y solución de las demandas estudiantiles, con el propósito de esbozar el sentido pragmático de los estudiantes para resolver expectativas a corto plazo, diferenciándolas de otras entidades políticas y estructurales contra quienes se pretendió actuar radicalmente en otros espacios.

10 Armando Moreno. "Ventanas al movimiento estudiantil en la Universidad de Sonora", páginas 313-316 en 154 años de movimientos estudiantiles en Iberoamérica. 11 Entre las escasas investigaciones locales que abordan estos espacios, la $\mathrm{MH}$ Nithia Castorena Sáenz describió y analizó dos grupos épicos dentro de la vida universitaria de la época: las sociedades Rosa Luxemburgo e Ignacio Ramírez, ambas de la Escuela de Leyes. Estas narraciones permiten entender la creación de espacios de reflexión y politización en la cotidianeidad. Véase: Estaban ahí. Las mujeres en los grupos armados de Chihuahua (1965-1973), páginas 153-165, UACJ, 2013. 


\section{LA HUELGA DE LOS CEBOLLEROS}

Mientras que entre los jóvenes fronterizos se acrecentó el menosprecio de la enseñanza agrícola, ${ }^{12}$ otros varones procedentes de provincia (conocidos como "los cebolleros") eran atraídos principalmente por las becas de la ESAHE, una de las pocas instituciones de educación superior en Juárez, fundada el 22 de febrero de 1906 por los hermanos agrónomos Numa y Rómulo Escobar Zerman. ${ }^{13}$

Eduardo Merrem, originario de ciudad Mante, Tamaulipas, llegó a la ESAHE en 1963, siguiendo a uno de sus hermanos mayores. Recuerda que al ingresar a la Hermanos Escobar se modificaron los requisitos para cursar estudios superiores:

[...] antes nosotros acabábamos de salir de secundaria y allá (en las universidades) nos recibían con la secundaria, no nos pedían la preparatoria. Pero ya después pedían la preparatoria para salir como ingenieros agrónomos [...] en ese entonces, había muchos agrónomos que habían salido y dominaban en todas las instituciones los presupuestos, las becas y ellos eran los que daban las becas para Ciudad Juárez.

Pablo Martell llegó de la huasteca potosina con su hermano Gustavo. Caracteriza al grupo de agrónomos notables como "altos funcionarios del sector agropecuario que influían para que esta escuela tuviera un subsidio muy bueno dentro de su presupuesto en aquella época, si no mal recuerdo de dos millones de pesos anuales y apoyos extraordinarios, en especie y en efectivo".

12 En 1964 se inauguró el Instituto Regional Tecnológico de Ciudad Juárez, que atrajo a un sector considerable de jóvenes que continuaban sus estudios técnicos o superiores.

13 Rómulo Escobar. Eslabonazos. Relatos y escenas de la vida campirana (1896-1936) 1. ${ }^{\text {a }}$ edición, Chihuahua, México, Secretaría de Educación y de Cultura, Gobierno del Estado de Chihuahua, 2001, 176 páginas. La información de esta cita es retomada del prólogo, autoría de Jesús Vargas Valdés. Los hermanos Escobar eran originarios de Ciudad Juárez y realizaron sus estudios agrónomos en Europa. En 1896 iniciaron la publicación de la revista mensual El Agricultor Mexicano, sobre cultivos y crianza de animales. La escuela Antonio Narro en Saltillo, Coahuila, la Nacional de Chapingo y la Hermanos Escobar fueron las instituciones formadoras de agrónomos en el México del siglo XX. Los Escobar fundadores fallecieron a mediados de la década de 1940. La administración de la ESAHE recayó entonces en Rómulo y Abelardo Escobar Villalba -hijos de Rómulo- y Rodolfo Escobar Calderón, hijo de Numa. 
Entre estos agrónomos prominentes figuraban César Martino, Felipe Salgado Pérez (entonces presidente nacional de la Sociedad Agronómica Mexicana), Julián Rodríguez Adame (exalumno de la ESAHE), sus directores Rómulo y Abelardo Escobar, así como el entonces Secretario de Agricultura, Juan Gil Preciado.

Las expectativas generadas en los estudiantes foráneos chocaron con las condiciones que encontraron en el internado. Eduardo Merrem recuerda que "la escuela llegó a tener mil y pico de alumnos, mil doscientos cincuenta alumnos, iy en unas condiciones terribles!, porque no había la capacidad para tener tantos; si nosotros éramos quinientos y pico, y ya no podíamos vivir gregariamente, hacinados, amontonados en las cavernas". Estas condiciones provocaron movimientos de huelga en 1957 y en 1963; Merrem participó en la segunda, exigiendo desde entonces la federalización del plantel. ${ }^{14}$

Pablo Martell recuerda que inmediatamente después de su arribo a la ESAHE:

[...] nos dimos cuenta que era una escuela que adolecía de muchas limitaciones, tanto del punto de vista económico como del punto de vista académico. Se manejaba como una escuela confesional donde si tú le sacabas la lengua al maestro te ponían de castigo encerrarte ¡a estudiar el fin de semana! Y la famosa beca que nos daban, que era una beca en realidad del gobierno federal, se la cobraban júnicamente como colegiatura! Entonces tenían ellos un sistema de internado que era un negocio iy había que pagar el internado! Había que pagar la comida, y había que pagar el alojamiento y todo era un negocio ahí. Como buena escuela confesional había un control de la sociedad de alumnos que servía únicamente para organizar el bailecito de aniversario y cosas así. No servía para defender los intereses de los estudiantes. Nosotros que ya íbamos de por acá con ciertas inquietudes, empezamos por formar un grupo que se llamó Avance.

14 Desde 1963 los estudiantes exigieron la federalización de la ESAHE. Julián Rodríguez Adame, el entonces secretario de Agricultura y Ganadería, se comprometió a la federalización con la firma de un documento, el cual desapareció de las oficinas directivas sin explicación alguna. El Fronterizo, jueves 11 de mayo de 1967, p. 2B. 
El guanajuatense Ricardo Valenzuela, integrante de dicho grupo estudiantil y creador del periódico mural, recuerda que:

Nos juntamos para analizar la situación de la escuela, vimos que adolecíamos de muchas cosas, empezamos a investigar un poco más, nos dimos cuenta que los libros que nos vendían a los becados deberían de ser gratis, que los gastos de excursión que teníamos que pagar estaban dentro de los gastos de las becas y así hubo otras muchas cosas. Tratamos de conseguir la mesa directiva.

Lo estudiantes y sus familias erogaban (a pesar de la beca y el subsidio) 350 pesos por colegiatura mensual, 200 por inscripción, "la venta de libros en el almacén de la escuela, ventas de apuntes, 125 pesos por el derecho de dormitorio, más lavandería y otros gastos". ${ }^{15}$ La biblioteca no se actualizaba y las prácticas agrícolas se reducían "a dos horas a dar azadonazos en una porción reducida de terreno", mientras que la institución recibía de subsidio dos millones doscientos mil pesos anuales. ${ }^{16}$ Los estudiantes concluyeron que la ESAHE funcionaba como una empresa particular.

Entre risas, los entrevistados aclaran que el grupo Avance no ganó las elecciones para mesa directiva. Los directivos de la EsAHE intentaron expulsar a los alumnos Rafael Carbajal y Arturo Camacho, acusándolos de llegar alcoholizados al internado. Los inculpados eran anarquistas, con inquietudes periodísticas y editaban unas hojas a manera de periódico, inspirados por el magonismo, desde el cual criticaban a los directivos Escobar. La inminente expulsión fue interpretada como advertencia a la disidencia. Eduardo Merrem recuerda que "la mesa estudiantil no luchó mucho por defenderlos, entonces los estudiantes logramos que no los corrieran". Por sugerencia de Pablo se formó un Consejo Estudiantil, con representantes de cada grupo. En asamblea se expusieron una serie de inquietudes, redactando inmediatamente un pliego petitorio en el que se demandaba:

15 El Fronterizo. "Están exigiendo que la ESA sea federalizada". Martes 9 de mayo de 1967. Portada y página 2 B. Ciudad Juárez, Chihuahua.

16 Ibíd. 
[...] evitar que se suspenda a los alumnos por la falta de pago a sus colegiaturas, se suprima el actual código disciplinario, por anacrónico; que se mejoren los edificios dormitorios los cuales no reúnen las más mínimas condiciones de habitabilidad; que se suspenda definitivamente a los profesores Hugo Almada Breach, Abelardo Escobar y Matías Ayala por ineptos y arbitrarios en sus decisiones de calificar a sus alumnos; que se mejoren los sistemas pedagógicos; que se paguen colegiaturas equitativas y que se mejore la calidad y número de libros de la biblioteca de la escuela. ${ }^{17}$

Pablo narra que:

[...] ya nos habíamos preparado, habíamos venido a Chihuahua con anticipación para informarles que nosotros íbamos a tener un movimiento de huelga en Ciudad Juárez. Incluso fuimos a una reunión de la Federación de Estudiantes de Agricultura a Ciudad Mante, Tamaulipas, donde se estaban reuniendo dirigentes de todo el país.

Dicha reunión se realizó el 29 de abril de 1967. Los cebolleros llegaron con el siguiente mensaje: "Vamos a estallar una huelga en la escuela y requerimos de su solidaridad". Por la mañana del 8 de mayo se celebró una asamblea en el auditorio encabezada por el presidente de la sociedad de alumnos, en la cual se presentó el pliego petitorio. En plena asamblea la dirección comunicó la expulsión de tres alumnos, entre ellos Pablo Martell, de reciente ingreso, y Eduardo Merrem, de sexto semestre. El Fronterizo ${ }^{18}$ informó que a las 9:30 de la mañana, un grupo de alumnos integrado por "Eduardo Merrem, Pablo Martell, Antonio Cabrera, Jorge Hernández Elías y Jaime Mendoza”, entregaron el pliego petitorio al director Rómulo Escobar en su oficina. "Al momento en que le fue entregado el pliego al director, este lo rechazó y abofeteó a uno de ellos", produciéndose un enfrentamiento físico entre estudiantes

\section{Ibíd.}

18 Los alumnos Jorge Hernández Elías y Fernando Carbajal, integrantes de la comisión de prensa y propaganda del Comité de Huelga, acudieron a las instalaciones del periódico para narrar lo sucedido. Visitar las redacciones de los periódicos fue una acción de propaganda común en los movimientos estudiantiles y populares de las décadas de 1960 y 1970. 
en pro y en contra de la huelga. ${ }^{19}$ Cerca del mediodía estalló la huelga. Los alumnos eligieron a Eduardo Merrem como presidente del Comité y a Pablo como secretario. Este narró emocionado:

Para darte una idea de cómo estábamos nosotros previendo la reacción de la dirección de la escuela, la reacción de los esquiroles y de las autoridades, nosotros mandamos hacer ¡doscientos garrotes! en forma de bates. Entonces cuando salimos de la asamblea ya para poner los sellos de clausura en los edificios llegaron los garrotes. Terminaron de repartirlos y empezaron los gritos: "ahí viene la policía, ahí viene la policía”, de tal manera que nos organizamos así, muy rápidamente, y tuvimos que enfrentar a la policía de Ciudad Juárez que, encabezados por el presidente municipal, ${ }^{20}$ ya venían a romper la huelga.

La directiva de la ESAHE declaró a la huelga como un movimiento liderado por estudiantes problemáticos y holgazanes. Se refirió a Eduardo Merrem y Pablo Martell como "un fósil que llegó de Tamaulipas a dirigir los mitotes" ${ }^{21}$ y "un alumno de triste historia", respectivamente, "ambos cabecillas de las agitaciones que ha habido en la ESA". Según Escobar, la expulsión de estos alumnos motivó el secuestro de los directivos durante todo el día, por lo que pidió la intervención de la policía, ${ }^{22}$ aunque posteriormente permitió la clausura de la escuela "para evitar cualquier atentado durante el movimiento huelguístico". ${ }^{23}$ Los alumnos cumplieron con los requisitos legales para declararse en huelga; "llegando la policía, entró el notario, entonces ya no pudieron hacer nada porque ya era legal en aquel momento. Levantó el acta y fue él quien puso los sellos en las puertas", recuerda Ricardo Valenzuela. Ante la acusación de manipular alumnos de los primeros grados, exhibieron un documento notariado con 420 firmas a favor de la huel-

19 Ibíd.

20 Armando González Soto fue presidente municipal de Juárez en el período de 1965 a 1968.

21 El Heraldo. "Secuestraron a los directores como protesta." Martes 9 de mayo de 1967. Portada y página 2. Chihuahua.

22 Ibíd.

23 El Fronterizo. "Fue clausurada la escuela de agricultura". Martes 9 de mayo de 1967. Portada y página 2B. Ciudad Juárez, Chihuahua. 
ga. Las instalaciones quedaron tomadas y la prolongación de la avenida Hermanos Escobar interrumpida a manera de barricada.

El 9 de mayo, al divulgarse la noticia de la huelga en la ESAHE, la demanda de gratuidad contrastó con la aprobación por el congreso estatal de un impuesto con monto del 4 por ciento, destinado a la Universidad de Chihuahua (UCH), ${ }^{24}$ impulsado por la movilización de los estudiantes, quienes pararon las escuelas. ${ }^{25}$ Los estudiantes agrónomos iniciaron una de las numerosas marchas que recorrieron la avenida de las Américas, la 16 de Septiembre y la Lerdo hasta el monumento a Benito Juárez. En ese primer mitin afirmaron que no cejarían en su lucha hasta lograr la federalización del plantel, ${ }^{26}$ es decir, "que la escuela se nacionalizara, que dejara de ser particular puesto que recibía un subsidio del gobierno federal muy importante, que se hiciera oficial", explica Martell. Repartieron volantes mimeografiados con los siguientes textos:

Compañeros: no permitamos ya que Escobar Hnos. y Cía., sigan incrementando sus fortunas a costa del sacrificio de nuestros padres. [...] la compañía recibe mensualmente $\$ 227,500.00$ por concepto de colegiatura y a cambio de tal cantidad recibimos si acaso el $50 \%$ en enseñanza efectiva. ¡Estamos en nuestro derecho a exigir lo que realmente nos corresponde! La Justicia nos asiste. [...] ha llegado el momento en que debemos luchar por nuestras reivindicaciones como estudiantes y por el mejoramiento de nuestra escuela. ${ }^{27}$

Como estrategia deslegitimadora, las autoridades y asociaciones agrónomas señalaron las influencias e "intereses extraños" sobre los alumnos por "agitadores bajo un plan deliberado", 28

24 Desplegado de agradecimiento a la XLVIII Legislatura de Chihuahua por parte del rector Russek, otros servidores públicos universitarios y presidentes de las sociedades de alumnos de las escuelas. El Heraldo, 10 de mayo de 1967.

25 El Norte. "Tregua de una semana en los paros de protesta de los universitarios". Domingo 7 de mayo de 1967.

26 El Fronterizo. "El mitin se llevó a cabo en orden; el Comité contra Huelga, actúa”. Miércoles 10 de mayo de 1967.

27 Fronterizo. "Están exigiendo que..."

28 El Fronterizo. "Es agitación premeditada, dice la Dirección de la Escuela". Martes 9 de mayo. Portada. En el transcurso de la huelga, los egresados integrantes de las agronómicas insistieron en señalar a los huelguistas como "[...] movidos por 
es decir, partidos y organizaciones de izquierda. Eso ocasionó que una mayoría de huelguistas se declararan reiteradamente apolíticos, ${ }^{29}$ sin experiencia política previa. En esas circunstancias, ¿cómo organizaron su movimiento? “¿Te imaginas darle de comer a cuatrocientos muchachos que están en huelga?", expresan azorados los entrevistados. 30 "El compañero tesorero sufría porque, ¿de dónde iba a sacar para darle de comer a todos?" Además de acopiar alimentos en los mercados, en un par de días reunieron $\$ 2100$ pesos "por boteo, gracias al pueblo de Juárez y del Paso". ${ }^{31}$ Organizados mediante brigadas y comités, realizaron mítines relámpagos, mantas, pintas en los puentes internacionales, visitas a asambleas escolares. Ricardo Valenzuela, integrante de la estudiantina, recuerda que tocaban en cabarets, centros nocturnos y en la calle "con una mano la guitarra o mandolina y en la otra, el bote".

Desde el inicio de la huelga, los alumnos en desacuerdo crearon un comité pro clases. Carlos Müller, Heberto Herrera y Rodolfo Pichardo, junto al profesor Francisco Montijo, constantemente anunciaban la reanudación de clases en colegios privados, lo cual no sucedió por consejo de los propios aliados de la ESAHE. Los huelguistas pidieron a Flavio Romero de Velasco, administrador de la Aduana Fronteriza, que fungiera de mediador con las autoridades de la Secretaría de Agricultura y Ganadería (SAG), que envió a una comisión "de carácter moral" integrada por veinte exalumnos de la ESAHE, con el ingeniero Felipe Salgado Pérez al frente,

hondos, profundos odios y resentimientos de carácter personal", manejados por políticos preocupados en agitar, señalando directamente al Partido Comunista o a quienes propiciaron "los lamentables hechos de Madera". Desplegado en El Fronterizo, página 5, 2 de julio.

29 Una comisión de los huelguistas de la ESAHE pasó a Chihuahua rumbo a México. El miércoles 10 de mayo llegaron Fernando Carbajal Chávez y Jorge Hernández Elías para solicitar el apoyo de los estudiantes de la Universidad. En las instalaciones del Norte declararon que "el movimiento es ajeno a cualquier agitación y todo el interés de los alumnos en huelga es la defensa de sus derechos como estudiantes de una profesión básica para la evolución, el desarrollo mejor y más rápido de la patria."

$30 \mathrm{El}$ acta notarial del inicio de huelga mostraba 420 firmas. El Fronterizo. "Sin solución viable la huelga de la ESA”. Sábado 13 de mayo. Portada y pág. 2 B.

31 El Fronterizo. Entrevista a Pablo Martell y Eduardo Merrem. Jueves 11 de mayo. Pág. 2 B. 
que arribó el 12 de mayo a Ciudad Juárez.32 Salgado (entonces presidente de la Secretaría Agronómica Mexicana y funcionario de la SAG) anunció que su propósito principal era lograr la reanudación de las clases. Parafraseando al presidente Gustavo Díaz Ordaz, Salgado exhortó a los alumnos a "terminar con las agitaciones y dedicar su tiempo al estudio para lograr la superación del país [...] Vamos a ver hasta dónde tienen razón los estudiantes y hasta donde no". ${ }^{33}$ El funcionario sentenció que si demandaban la federalización, iniciaran el trámite ante instancias correspondientes y regresaran a clases. Pero si continuaban con su "proceder intransigente", el Secretario Juan Gil Preciado no los recibiría. ${ }^{34}$ Los huelguistas respondieron: "o se cumplía la federalización del plantel o nada". ${ }^{35}$ La huelga continuaría. Conformaron una comisión que se trasladara a la Ciudad de México para encontrarse con el secretario.

Pareciera que las autoridades no esperaban las muestras de solidaridad que no tardaron en llegar. A las guardias se unieron estudiantes de las preparatorias diurna y nocturna, ofreciendo su respaldo moral y económico. La Federación Estudiantil de Chihuahua (FECH) comisionó a José Luis Aguayo, José Socorro Gutiérrez y Martiniano Galaviz para que acudieran a la ESAHE a respaldar la huelga, además de comprometerse a mandar telegramas, ayudar económicamente y difundir las demandas en todas las escuelas. ${ }^{36}$

Una semana después arribó la presencia nacional, con representantes de la Federación de Ciencias Agropecuarias y Forestales (FNECAF) y de la Escuela Nacional de Agricultura de Chapingo (ENA), además de la Federación de Estudiantes Juarenses (FEJ), el Instituto Tecnológico de Ciudad Juárez y diversas secundarias, ofreciendo apoyo moral y financiero, además de paros escalona-

32 La Comisión estaba integrada además por César Martino Torres, Felipe Salgado Pérez, Francisco García Uribe, Ferrer Galván Bourrel, Rubén Carrillo Briones, Luis Fernández Calleros, Mónico Ríos Rosales, Arturo González Pérez, Mauro Ruiz Ayala y Genaro Castro Arrayales.

33 El Fronterizo. "Sin solución viable ..."

34 El Fronterizo. "Si quieren federalización, deben seguir cauces normales: Salgado Pérez". Domingo 14 de mayo. Portada y página 2B.

35 El Fronterizo. "Federalización o seguimos en huelga". Domingo 14 de mayo. Portada. 36 El Fronterizo. "El estudiantado chihuahuense apoya el paro". Lunes 15 de mayo. Portada. 
dos en las actividades de sus instituciones. ${ }^{37}$ Esas muestras de solidaridad alertaron a la Comisión. El agrónomo Salgado Pérez declaró que "el problema era grave" y apeló a "la intervención de los hijos de ESA", ${ }^{38}$ quienes publicaron el 16 de mayo un telegrama dirigido al secretario Juan Gil Preciado.

Los abajo firmantes ex alumnos ESAHE, respetuosamente le comunicamos, no apoyamos movimiento huelguista, provocado en su mayoría (por) menores de edad que piden su federalización, manejados (por) líderes influenciados (por) factores externos ajenos (a) dicha Escuela, que están incapacitados definir su destino, juzgarla y abrocarse (el) derecho (a) difamarla [...] Suplicamos considerar que intereses afectivos, morales y la opinión de cuatro mil egresados son superiores a los de 400 estudiantes al dictar resolución a problemas reales (de) nuestra escuela, si éstos existan, ofreciéndole nuestra cooperación desinteresada para su superación [...] Atte. Sección Chihuahua de la Asociación de Agrónomos e Ingenieros Agrónomos de Ciudad Juárez. El Secretario. Ing. Jorge A. Máynez L. ${ }^{39}$.

El encuentro solicitado con Gil Preciado fue negado, condicionándolos a dialogar en Ciudad Juárez con la comisión de agrónomos, único conducto oficial para la resolución del conflicto. Como respuesta, los huelguistas realizaron al día siguiente un mitin en el monumento a Juárez y alumnos de la Escuela Antonio Narro de Saltillo se declararon en huelga. Gil Preciado anunció que recibiría a los huelguistas. Las descalificaciones en los discursos se atenuaron, aunque continuó la insistencia para reanudar las clases debido a la proximidad de los exámenes. "Es tiempo de recuperar lo perdido. No pretendemos alejarlos de la lucha por sus propósitos e ideales [...] pueden seguir en la discusión de sus demandas y en su lucha por la federalización", publicaron los agrónomos

37 El Fronterizo. "La huelga adquiere caracteres nacionales". Martes 16 de mayo. Portada.

38 El Fronterizo. “En sesión permanente los agrónomos locales". Lunes 15 de mayo. Portada.

39 El Fronterizo. 16 de mayo de 1967, p. 7A. Las palabras entre paréntesis fueron agregadas para su comprensión. 
egresados de la ESAHE. ${ }^{40}$ La Comisión, apelando "a su responsabilidad, cordura, prudencia, comprensión y generosidad” solicitó:

[...] que vuelvan a la normalidad de las actividades docentes en nuestra querida Escuela, con el objeto de que todos los alumnos, hermanos menores nuestros, sigan capacitándose en las aulas para mejor servir a los intereses del campesinado. Amparados bajo el esbelto ejemplo de los próceres que hicieron posible hace cien años el triunfo de la República, los exhortamos fraternalmente a que con hechos concretos de conducta, hagamos honor al compromiso ineludible que todos tenemos como ciudadanos de supeditar todo interés personalista o de grupo a los intereses superiores de México. ${ }^{41}$

Los jóvenes destinatarios de estos mensajes respondieron:

Distinguidos señores: Hemos conocido su carta en la cual nos invitan a claudicar -esta es la palabra precisa- por más que se trate de llamar a esto: tener cordura y prudencia o tener alto sentido de comprensión y generosidad [...] Ojalá tengáis la conciencia tranquila. Ustedes afirmaban que jamás harían el papel de rompehuelgas, ¿Cómo puede considerarse su llamado sino como un intento de romper nuestra huelga? El problema existe, nosotros no luchamos por crearlo, sino porque se solucione. Lucha por el campesinado. Comité de Huelga, Eduardo Merrem. ${ }^{42}$

En un lapso de poco más de dos meses que persistió la huelga, la condición de regresar a clases y la limitada capacidad de resolución de la Comisión, frustró cualquier intento de diálogo con los alumnos huelguistas. Desde finales de mayo, el movimiento estudiantil se disputó en dos espacios: la ESAHE, donde siguieron llegando delegaciones de alumnos agropecuarios, forestales, tec-

40 Entre los firmantes se encontraban Francisco Montijo, Matías Ayala, Luis Borjón, Ernesto Sáenz, Francisco Navarro, Sergio Maeser, María Elena Almanza, Filiberto Terrazas. El Fronterizo. 20 de mayo de 1967, p. 6B.

41 Ibíd.

42 El Fronterizo. 20 de mayo de 1967, p. 2 B. 
nológicos y normalistas, ${ }^{43}$ así como el monumento a Juárez, en donde iniciaron una huelga de hambre. ${ }^{44}$

El otro lugar de movilización y negociación fue el Distrito Federal, hasta donde llegó una comisión más numerosa de huelguistas con adiciones al pliego petitorio: la construcción de un nuevo plantel (ya fuera en Chihuahua o Delicias) federalizado y administrado por la SAG y la UCH; garantizar el regreso a clases sin represalias, la destitución de Rómulo Escobar como director así como el cese de los maestros no calificados. Surgieron los rumores de que la ESAHE desaparecería. ${ }^{45}$

\section{LA HUELGA SE EXTIENDE}

Llegó el mes de junio y parecía en Ciudad Juárez la huelga perdía apoyo. Sin embargo, estudiantes de diversas instituciones intensificaron las acciones para presionar a la SAG. ${ }^{46}$ Chapingo se declaró en huelga el día 5. Los representantes estudiantiles acordaron la huelga indefinida en todas las escuelas agropecuarias restantes. Los estudiantes agrónomos lograron sostener la huelga pese a que la SAG ordenó el cese de los servicios de comedor o la intervención de la policía. Esta segunda etapa de movilizaciones nacionales fue encabezada por la Federación Nacional de Estudiantes de Ciencias Agrícolas y Forestales (FNECAF), la Federación de Estudiantes Campesinos Socialistas de México (FECSM) y la Confederación Nacional de Estudiantes Democráticos (CNED), ${ }^{47}$ "que en aquella época encabezaba las luchas más importantes a

43 El Fronterizo. "Hoy puede hacer crisis la huelga de Agricultura, aquí". Viernes 19 de mayo.

44 El Fronterizo. "Ganar o morir". Domingo 28 de mayo.

45 El Fronterizo. "Los dueños de la ESA dispuestos a lograr un trato". Sábado 27 de mayo.

46 Sobre el apoyo a la huelga de a ESAHE en el Distrito Federal y Chapingo encontré escasa información, entre esta la del investigador Gerardo Peláez Ramos (Departamento de Sociología de la UAM-Iztapalapa), quien en su artículo "1967: la huelga estudiantil de las escuelas de agricultura, el Politécnico, las normales rurales y otras instituciones" (6 páginas), abordó la movilización desde la huelga en las ESA y posteriormente en el IPN a través de la revista Política y de La Voz de México, periódico del Partido Comunista Mexicano (PCM). http://www.lahaine.org/ b2-img12/pelaez_huel_est.pdf (consultado el 6 de febrero de 2016).

47 Ibíd., p. 2. 
nivel nacional", recuerda Martell. En la CNED participaban alumnos de escuelas politécnicas disidentes de la Federación Nacional de Estudiantes Técnicos (FNET). ${ }^{48}$ Jesús Vargas Valdés (entonces estudiante de Ciencias Biológicas) recuerda que "las brigadas de los estudiantes de Ciudad Juárez se presentaron en algunas de las escuelas del Politécnico", ${ }^{49}$ celebrándose el 29 de junio una asamblea en la Escuela Superior de Ingeniería Mecánica y EléctriCa (ESIME), en la cual se informó que la SAG ofrecía reformas académicas y administrativas al interior de la ESAHE. ${ }^{50}$ Rechazaron la oferta y a principios de julio se declaró la huelga en las

[...] Escuela Superior de Ciencias Físico-Matemáticas, Escuela Superior de Economía, Escuela Superior de Ingeniería Textil, Escuela Superior de Ingeniería Mecánica y Eléctrica, Escuela Nacional de Ciencias Biológicas, Escuela Preparatoria Técnica Piloto (Cuauhtémoc), Pre vocacional 7, Vocacional 14, Pre vocacional 4, Vocacional 5 y las secundarias 16 y 83 de Tlatelolco. [...] En la Escuela Nacional de Maestros, la Escuela Normal Superior y algunas secundarias se produjeron paros escalonados. ${ }^{51}$

Para Vargas Valdés, "fue la ESFM la que encauzó el movimiento en el Politécnico, poniéndose en práctica las formas de organización de cada escuela. El modelo de distribuir las tareas a través de comisiones, así como la formación de brigadas para informar y recolectar fondos, surgieron de esta huelga". ${ }^{2}$ Pablo Martell considera que "no vimos la dimensión que tuvo. Fue un antecedente muy importante para diseñar la dirección del 68, porque el movi-

48 En su texto La patria de la juventud, Jesús Vargas Valdés realiza un esbozo del proceso en el cual surgió la FNET en 1956, inmediatamente después del asalto militar del IPN, hasta principios de la década de 1960 que se convirtió en una federación "charra" sin independencia, profundamente relacionada con las autoridades priistas a nivel nacional, aunque se consideraba como la representación de los estudiantes del Instituto Politécnico Nacional, de los Institutos Tecnológicos Regionales y de las Escuelas Técnicas Industriales y Comerciales del país. Vargas considera que la FNET no superó la insurrección de los estudiantes opositores del Congreso de diciembre de 1967 en León, Guanajuato. Ver página 92.

49 Página 88.

50 Peláez. 1967: la huelga... p. 3.

51 Ibíd.

52 Vargas. La patria... p. 92. 
miento de solidaridad del nuestro, fue encabezado por un Comité Coordinador Estudiantil que se gestó precisamente en la Escuela de Físico Matemático del Politécnico".

Gilberto Guevara Niebla, dirigente estudiantil de Ciencias de la UNAM y delegado frente al Consejo Nacional de Huelga en 1968, escribió de la huelga precedente:

Este conflicto local suscitó, inopinadamente, uno de los impresionantes movimientos de solidaridad estudiantil pues, del 8 de mayo al 15 de julio, la huelga nacional alcanzó a incorporar a 70000 estudiantes de todo el país, incluyendo a los alumnos del Instituto Politécnico Nacional en donde, después de 11 años de paz interior, se declaró una huelga general. Junto al IPN participaron: la Escuela Nacional de Agricultura (Chapingo), las escuelas de agricultura de todo el país, las normales rurales, la Normal Superior, etc. La lucha se organizó a través de un Consejo Nacional de Huelga y Solidaridad que sería el antecedente inmediato del $\mathrm{CNH}$ de $1968 .{ }^{53}$

Esa semana de huelga nacional en el IPN y las ESA fue determinante para presionar a la SAG. La sorpresa fue la intervención del gobernador Práxedis Giner Durán, ausente en el transcurso de la huelga. El 10 de julio se trasladó a Ciudad Juárez para reanudar las clases de agronomía, que iniciaron bajo responsabilidad de maestros y alumnos en el Colegio Bernal. Lo acompañó el rector universitario Manuel Russek, quien declaró que reconocería las clases pese al reclamo de los huelguistas. Por segunda ocasión, los diarios anunciaron la desaparición de la ESA en enero de 1968, formando parte de la UCH.

Pablo Martell recuerda que

Rodolfo Posadas Báez, Alberto Legazpi y yo estábamos negociando en Chihuahua con el gobernador a través de Héctor Valles y por ahí se fue perfilando como la creación de la Facultad de Agronomía de la Universidad de Chihuahua, como posible solución, y que nos absorbiera junto con el subsidio que recibía la Escuela Hermanos Escobar. Nosotros teníamos la intención de aceptar esa posible solución

53 Gilberto Guevara, La democracia en la calle, p. 34. 
pero había que plantearla a la asamblea, allá en Ciudad Juárez. El estudiantado aceptó y nos sentamos con el rector de la Universidad, Manuel Russek, a elaborar un convenio, y en ese convenio nosotros planteamos fundamentalmente tres cosas: creación de escuela, construcción de edificio para la escuela y el sistema becario, eso era central y ellos nos aceptaron las tres cosas. Eso se plasmó en el convenio y se firmó ahí, delante de todos los estudiantes en el auditorio de la escuela de los Hermanos Escobar con la presencia del Rector de la Universidad.

A las 23:30 horas del sábado 15 de julio se firmó el convenio, un documento leído por el administrador de aduanas Favio Romero de Velasco. En ocho puntos, la UcH se comprometió a crear de inmediato la Escuela de Agronomía, cuyo edificio debería estar construido definitivamente para enero de 1968: legalizar el traslado de los estudiantes desde Ciudad Juárez, resolver el problema de su hospedaje y alimentación, reconocer los estudios cursados en la ESAHE, así como administrar y gestionar un aumento en el subsidio que otorgaba la SAG exclusivamente para la Escuela de Agronomía. Por su parte, los estudiantes adquirían los derechos y obligaciones previstos en la Ley Orgánica de la UcH. ${ }^{54}$ Manuel Russek firmó en representación de la universidad, Martell y Merrem por parte del Comité de Huelga. Arturo Torres por la FNECAF y un representante de los estudiantes del IPN firmaron como testigos del acuerdo. ${ }^{55}$

Las noticias anunciaron que 180 alumnos huelguistas dejaron la ESAHE. ${ }^{56}$ Pablo Martell recuerda que "[...] entonces nos pusieron unos camiones para que nos trasladáramos a Chihuahua con todo y chivas", en uno de los cuales viajaba el rector Russek, mientras Romero de Velasco fue el encargado de entregar las instalaciones al director Escobar. Varios empleados de la ESAHE también eligieron el nuevo proyecto, como "Don Chuy", el cocinero del

54 Peláez. 1967: la huelga... p. 4.

55 El Fronterizo. "Terminó la huelga en la ESA". Domingo 16 de julio. Portada.

56 El Fronterizo. "Salieron a Chihuahua los huelguistas". Martes 18 de julio. Portada. 
internado, y la señora "Doña Ofe", quien vendía los tacos. Atrás quedó la Escuela de Agronomía Hermanos Escobar. ${ }^{57}$

De los primeros recuerdos en esa nueva etapa, Martell señala que Olac Fuentes Molinar, entonces jefe de Relaciones Públicas de la UCH, se convirtió en el funcionario clave para el funcionamiento de la nueva escuela que, oficialmente, se fundó el 22 de julio de 1967, aunque las clases para 125 alumnos iniciaron el lunes 24. Los recién llegados presentaron exámenes para acreditar los cursos semestrales interrumpidos por la huelga. Felipe Vázquez Mancinas, especialista en suelos, fue nombrado director de la Escuela de Agronomía. La planta docente se integró con los propios profesores de la universidad..$^{58}$

[...] nos dimos a la tarea de reforzar la planta académica con maestros como Aquiles Córdova y Pedro Zapata Vaqueiro que habían sido

57 Después de la huelga, se constituyó una asociación civil de alumnos que adquirió los derechos y bienes de "Hermanos Escobar y Cía.", quienes continuaron como profesores. En 1970, el gobierno federal otorgó por comodato un terreno de casi 49 hectáreas (conocido como La Cuesta) en la entrada a Ciudad Juárez. Cuatro años después abandonaron las antiguas instalaciones de La Playa. Continuó como institución privada, con subsidio de las secretarías de Agricultura y Educación, aunque no contó más con servicio de internado. La UACH, mediante convenio, reconocía los estudios cursados y expedía los títulos profesionales. En 1982 estalló una nueva huelga, cuyo comité lo dirigió Cuauhtémoc Reyes Castro. Tomaron las instalaciones, desconocieron a las autoridades y la asociación civil, disponiendo de los recursos federales. Un año después, de facto existieron dos proyectos Hermanos Escobar: el de la ESAHE, A. C., que regresó a las viejas instalaciones, y el de Reyes Castro en el nuevo campus. Estos últimos lograron que la Universidad de Chapingo firmara convenio de incorporación reconociendo los estudios -entonces gratuitos- aunque dicha relación fue cancelada en 1989. A finales de 1992, en un contexto de transición electoral estatal con la gubernatura del panista Francisco Barrio, se generó un conflicto entre Reyes Castro -entonces militante priista- y un grupo de estudiantes y profesores opositores, lo cual generó el cierre definitivo (de esta nueva generación de la década de 1980 provienen varios dirigentes del movimiento campesino chihuahuense actual). En 1993 el terreno e instalaciones fueron cedidos al municipio de Ciudad Juárez, en donde se acondicionó el Parque Central, quedando únicamente el edificio de la biblioteca, en la que actualmente funciona una preparatoria. Los integrantes de la Asociación Nacional de Egresados de la ESAHE continúan realizando gestiones para una sede física y las conmemoraciones. 58 La estructura académica de la UCH contaba con seis escuelas profesionales: Derecho, Ingeniería, Medicina, Ganadería, Contabilidad y Administración, Filosofía y Letras (ésta última también recién incorporada); cinco subprofesionales: Enfermería y Obstetricia, Técnico Ganadero, Educación Física, Técnico Químico y Agronomía; un Instituto de Bellas Artes y una Escuela Preparatoria. 
dos líderes muy importantes de Chapingo, que ya habían egresado, ya eran profesionistas y nos los llevamos como maestros en la escuela, como una garantía de que la escuela continuara con sus proyectos adelante. No teníamos líneas de investigación puesto que éramos una escuela nueva, pero compartíamos la inquietud sobre que el problema agropecuario del país no era técnico, sino de carácter social fundamentalmente, y en ese sentido promovíamos el conocimiento social como una palanca para resolver incluso los problemas técnicos. ${ }^{59}$

A través de las entrevistas percibimos cómo la memoria grupal es construida desde el triunfo del movimiento. Rememoran el baile de presentación ante la sociedad chihuahuense en el Hotel Victoria. Durmieron y tomaron clases en los salones prestados del Instituto de Bellas Artes. Según los entrevistados, las acciones de solidaridad entre los propios estudiantes no terminaron con la huelga,

[...] de tal manera que creamos una Casa del Estudiante Agrónomo cuando llegamos a Chihuahua. Rentamos una casota de catorce cuartos durante ocho años, en la Calle Novena, ahí cerca del jardín (Parque Revolución) ese donde está la capilla de Villa. Nos pusimos a vivir ahí, no sé si veintitantos o treinta y tantos compañeros. ${ }^{60}$

Recuerdan actividades en las que se involucraron, como el manejo de ganado, deportes, canto, oratoria, música, teatro y la propia radio universitaria.

\section{NOSOTROS VENIMOS A REVOLUCIONAR LA UNIVERSIDAD}

Los protagonistas basaron su identidad frente a los otros en la victoria de la huelga. Pablo Martell enfatiza:

59 Pablo Martell Santos, 23 de marzo de 2014.

60 Durante la entrevista se relató la instalación de esa casa donde vivieron por varios años algunos de los estudiantes agrónomos. Interpreto que fue un proceso autogestivo y solidario, que se reprodujo similarmente con el resto. Sin embargo, en años sucesivos se siguió demandando el establecimiento de casas para estudiantes de escasos recursos subsidiadas por recursos federales. Este aspecto queda pendiente de historiarse, aunque otros ejemplos anteriores los podemos encontrar en la investigación de Aleida García, La revolución que llegaría, con población estudiantil normalista. 
Nosotros llegamos a revolucionar la universidad, la universidad era muy tranquila cuando nosotros llegamos, éramos gente pesada en los movimientos estudiantiles. Claro, los compañeros de Leyes dirigidos por los Nachos, donde destacaba (Jaime) García Chávez, Víctor Orozco, el profesor (Rogelio) Luna, "Los Churriques" (Enrique y José Luis) Pallares. En Zootecnia estaba Nacho González, Roberto Sepúlveda era de la Facultad de Ingeniería y Marco Rascón en la Escuela Preparatoria. Además había mucha actividad y amistad con el grupo que fundó la colonia (Francisco) Villa.

Al término de las entrevistas, pensé que analizar y reconstruir un movimiento victorioso era un reto para alguien que investiga organizaciones de izquierda radical bajo el prisma de la derrota. Envié un primer borrador a un amigo historiador, quien me advirtió del silencio de mis actores sobre el incumplimiento de la SAG de los acuerdos firmados en julio de 1967. ¿Por qué los entrevistados no mencionaron que las autoridades federales no depositaron los recursos acordados a la UcH? Me pregunté: ¿Cuál memoria se deseaba construir al omitir el incumplimiento de las demandas?

A través de la revisión de fuentes primarias se aprecia la negación de directivos y autoridades agrícolas cercanas a la ESAHE para renunciar a los recursos federales. A pesar de los acuerdos firmados en julio de 1967, Rómulo Escobar declaró que "de buena fuente, sabía que las becas se seguirían pagando”. En consecuencia, en febrero de 1968, la SAG anunció que otorgaría 150 becas para estudiantes de todo el país que ingresaran a la ESAHE. ${ }^{6 \mathrm{I}} \mathrm{El}$ secretario Gil Preciado agradeció "el apoyo prestado al gobierno federal, tanto en el aspecto técnico de su carrera como en el social y político, caracterizado por su actitud netamente revolucionaria y nacionalista, siempre ajena a las corrientes ideológicas extrañas a nuestra idiosincrasia”. El 23 de febrero, después de las declaraciones oficiales, los estudiantes de Agronomía de la UCH estallaron una huelga para exigir la erogación de aproximadamente un millón quinientos mil pesos, las dos terceras partes de los recursos negados, pese a las gestiones del gobierno del estado

61 El Norte. "150 becas para estudiantes de la ESA de Ciudad Juárez". Portada. 2 de febrero de 1968. 
y la Universidad. ${ }^{62}$ Cinco días después, los estudiantes de Leyes se declararon en huelga siguiéndolos a manera de paros las escuelas de Ganadería, Ingeniería, Técnico Química, Zootecnia, Filosofía y Letras, la Secundaria 1 y las preparatorias diurna y nocturna, así como la Normal del Estado. Los representantes estudiantiles integraron el Comité Universitario de Huelgas y Paros (CUHP) con el fin de coordinar las actividades estudiantiles, bajo el lema "Solidaridad estudiantil por la universidad".

Los alumnos huelguistas declararon que su movilización se basaba en el derecho al subsidio completo para evitar la disminución del patrimonio universitario, ya que a pesar de las medidas tomadas por el rector Russek, el Consejo Universitario y el propio gobernador admitieron que las propuestas de la SAG eran ambiguas, pues en ocasiones se referían a "subsidios" y otras a "becas". Pese a ello, las autoridades pidieron reanudar las clases y aceptaron la propuesta de un millón 200 mil pesos anuales, treinta hectáreas de la posta zootécnica, así como la compra de equipo para laboratorio y prácticas de campo. Rectoría aprovechó los hechos para advertir a los estudiantes huelguistas que en un futuro inmediato "[...] la escuela de agronomía no será objeto de ningún trato preferencial por razones de orden extra académico [...]”.

Los estudiantes delegados en el cuHP hicieron pública su postura: esperarían quince días para que las autoridades universitarias presentaran documentos oficiales que garantizaran la efectividad de los acuerdos, de lo contrario declararían la huelga, la cual se mantuvo únicamente en el plantel de Agronomía. Con el vencimiento del plazo, iniciaron nuevamente los paros. El comité de huelga de Agronomía responsabilizó al secretario Gil Preciado de la salud de 16 alumnos en huelga de hambre. Debido a la falta de interlocución y la proximidad del fin de clases, los cuatro mil alumnos en huelga (la mitad eran estudiantes de la Preparatoria) propusieron buscar otra forma de presionar a la SAG. Confirmada la entrega de becas, subsidio y posta zootécnica, terminó la huelga el 15 de abril, después de seis semanas. Los estudiantes acordaron constituir un Consejo Estudiantil para dirigir las ac-

62 El Norte. "Protesta de agronomía por falta de subsidio federal". 24 de febrero de 1968. 
ciones en contra de la SAG, evitar represalias y estar atentos a las presiones de grupos como la agronómica, cercanos a la ESAHE. ${ }^{63}$

La movilización estudiantil del 68 irrumpió de nuevo en la UCH en plena primavera, tras subsidios y becas de manutención, en una acción de presión contra autoridades federales agropecuarias y gremiales a las que pensaron rendidas. Agradecidos con la UCH por su recepción, especialmente con su rector, el campo de batalla lo caracterizaron como "estrictamente universitario", aunque algunos alumnos militaban en la movilización popular de la colonia Francisco Villa. La insurgencia seguía prendida en la sierra de Chihuahua. Sin embargo, los sucesos protagonizados por el Grupo Popular Guerrillero Arturo Gámiz (GPGAG), un pequeño grupo rural insurgente de varones jóvenes (entre quienes destacaban como exalumnos universitarios Óscar González Eguiarte y Carlos Armendáriz Ponce), no originaron muestras públicas de solidaridad. Las noticias sobre el incendio del aserradero "La Palillera” en Tomochic ${ }^{64}$ por parte del GPGAG, la incursión del ejército federal en la sierra con el objetivo de rastrearlos y aniquilarlos, se perdieron entre las crónicas diarias del movimiento estudiantil de la capital del país, iniciado a finales de julio de 1968.

La respuesta del gobierno federal al movimiento estudiantil de la capital de México iniciado el 22 de julio se recrudeció después del 18 de septiembre, cuando el ejército desalojó a los estudiantes y permaneció en las instalaciones universitarias. Un día después en Chihuahua, en protesta, marcharon tres mil estudiantes de la Universidad, el Tecnológico, la Normal del Estado y la rural de Salaices. Ese mismo día se anunció que las sociedades de alumnos de Derecho y de Agronomía, junto a la FECH, serían anfitriones del "II Encuentro Nacional Democrático Estudiantil (ENDE)," en el cual esperaban a cerca de 300 dirigentes nacionales. ${ }^{65}$ Jesús Vargas, enviado por la asamblea politécnica, recuerda

63 El Norte. “Terminada la huelga se normalizarán las labores”. Miércoles 17 de abril de 1968. Portada.

64 El 30 de julio, un millar de alumnos de la Normal del estado, marchó silenciosamente por el arresto del profesor Leocadio Carlos Núñez Moreno, acusado de participar en la quema del aserradero.

65 El lema del encuentro fue: "Por una educación democrática, en un México democrático". 
que el encuentro no se realizó debido a la falta de asistencia. La minoría que llegó decidió recorrer diversos planteles de la ciudad, informando sobre el movimiento estudiantil. Vargas asistió al Tecnológico y a la Preparatoria.

A principios de octubre, tres días después de la violenta embestida estatal al mitin en Tlatelolco, Agronomía y Derecho se declararon en huelga indefinida, ${ }^{66}$ uniéndose sorpresivamente el estudiantado de Administración y Contabilidad, así como de la Preparatoria. En las marchas se exigió la libertad de los presos políticos, especialmente de Sergio Seáñez, alumno de Técnico Química, detenido en la ocupación de la UNAM y consignado en el Distrito Federal. Las autoridades universitarias declararon la suspensión de clases para sintonizar las Olimpiadas, reanudándose a finales de octubre.

\section{LOS UNIVERSITARIOS, ENTRE LA RADICALIDAD POLÍTICA Y EL MOVIMIENTO POPULAR}

El surgimiento de organizaciones políticas armadas de carácter preponderantemente urbano surgió a finales de la década de 1960, con la primera generación del Movimiento de Acción Revolucionaria (MAR). Iniciada la nueva década y tras el rompimiento de jóvenes comunistas con el Partido Comunista Mexicano (PCM), redes finas iniciaron el tejido de organizaciones regionales o nacionales que proyectaron como futuro la revolución socialista. Algunos pioneros provenían del movimiento estudiantil de 1968 (los Lacandones y el Grupo N), de movilizaciones posteriores, locales y simultáneas, como el Frente Estudiantil Revolucionario (FER) en Guadalajara o la Comisión Coordinadora Clandestina de la Federación de Estudiantes Universitarios Sinaloenses (FEUS). El 10 de junio de 1971 en el Distrito Federal, un grupo paramilitar reprimió una marcha organizada como espejo solidario para exigir reformas en la ley orgánica de la Universidad Autónoma de Nuevo León, tendientes a la paridad entre maestros y estudiantes en

66 El Heraldo. "Agronomía y leyes en huelga". Sábado 5 de octubre de 1968. Portada. Los principales detractores eran padres de familia que demandaban mano dura contra los líderes, entre ellos los recién llegados agrónomos. 
el Consejo Universitario; la elección directa, individual y secreta para autoridades; reconocimiento de derechos laborales y el 12 por ciento del total del presupuesto fiscal anual. ${ }^{67}$

Pablo Martell recuerda que precisamente en 1971, invitado por las hermanas Martha y Alicia de los Ríos, se reunió con Raúl Ramos Zavala, joven economista, exdirigente de la Juventud Comunista de México (JCM), quien entonces organizaba una coordinación político-militar a nivel nacional. "A pesar de las derrotas del movimiento estudiantil y popular, no estuve de acuerdo en que la vía política estuviera cerrada [...] lamentaba mucho no coincidir con él", platica Pablo. Una mayoría desconocía que en la misma red clandestina participaba el ingeniero chihuahuense Diego Lucero Martínez.

Meses después, el 14 y 15 de enero de 1972, se intentó expropiar bancos en Monterrey y Chihuahua, respectivamente. En los comandos chihuahuenses participaron jóvenes universitarios, como Mario Holguín, Marco Antonio y Javier Pizarro, Marco Rascón, Avelina Gallegos (quien murió en una de las sucursales) y Lucero Martínez, ejecutado después de ser detenido y torturado. Los homicidios se presentaron ante la opinión pública como enfrentamientos y suicidios. Debido a las trayectorias escolares de los militantes, autoridades de Rectoría llamaron a defender la universidad contra el terrorismo y solicitaron a los paterfamilias vigilancia para sus hijos estudiantes, "jóvenes de corta edad que se ven envueltos por gente interesada en cometer delitos". 68 Inmediatamente, centenas de estudiantes se entrevistaron con el gobernador Óscar Flores y el rector Óscar Ornelas. Alumnos de Derecho integraron la defensa de los detenidos y otros una comisión coadyuvante para las investigaciones. El 9 de febrero iniciaron las manifestaciones estudiantiles, encabezadas por el Comité Coordinador Estudiantil de Enseñanza Superior (CCEES),

67 Ver 1971: el año de los jóvenes regios, de Ana Lucía Heredia. (Consultado el 22 de septiembre de 2016. http://www.elbarrioantiguo.com/1971-el-ano-de-los-jovenesregios/ Sobre el movimiento estudiantil en Monterrey, la guerrilla y el empresariado, es imprescindible la consulta a las investigaciones de Óscar Flores, de la Universidad Autónoma de Coahuila.

68 El Norte. "Lamenta la Universidad los trágicos acontecimientos." Martes 18 de enero de1972. 
integrado por los presidentes de sociedades de alumnos de escuelas universitarias, del Tecnológico y la Normal del estado. Exigieron la destitución del Procurador Antonio Quezada Fornelli y el inspector general de la policía, Ambrosio Gutiérrez, señalados como responsables de las muertes de los jóvenes. Esas movilizaciones fueron el origen de la Asamblea Popular y el Comité de Defensa Popular, integrado por estudiantes, la colonia Villa, obreros y maestros de diversos sindicatos y otras organizaciones.

El 15 de febrero estalló una huelga en la preparatoria que alcanzó a toda la Universidad. ${ }^{69}$ Se exigió un consejo universitario integrado por el mismo número de alumnos y profesores (entonces duplicado por maestros); la abolición de la junta de gobierno (que escogía a los rectores por decisiones extrauniversitarias); auditorías a diversas secretarías universitarias y al patronato; alternativas de ingresos que permitieran reducir el monto de las inscripciones, así como becas para hijos de campesinos y obreros; solicitudes específicas sobre la infraestructura de la preparatoria, así como una dirección colegiada que sustituyera la unipersonal.

La huelga perduró hasta el 6 de marzo, después de que la mayoría de claustros de maestros, renuentes a permitir la paridad al interior del consejo universitario, la aprobó finalmente. Desapareció la junta de gobierno universitaria y se votaron a favor otras demandas, como instalar el departamento vocacional en la preparatoria, integrar comisiones de alumnos y profesores para las auditorías y propuestas de ingresos. El Consejo de Huelga suscribió:

[...] La huelga, como método de lucha, ha cumplido sus funciones [...] deseamos no tener que recurrir a las vías de hecho para la solución de nuestros problemas. Pero manifestamos, que cuantas veces sea necesario, que cuando por la vía del convencimiento no logremos hacer escuchar nuestras voces, estaremos dispuestos no sólo a utilizar la huelga como táctica de lucha, sino asumir posiciones más radicales, ya que el fundamento de nuestras acciones se ve avalado por la justeza de nuestros principios.

69 Es interesante observar que los estudiantes de Agronomía solicitaron dialogar con el rector antes de incorporarse a la huelga. Después del encuentro con Ornelas, se unieron a la movilización. 
La movilización estudiantil de nivel medio superior y superior de Chihuahua giró en torno a la demanda de participar en la resolución de conflictos. Finalizado el movimiento universitario, estallaron las huelgas en el Instituto Tecnológico y la Normal del estado: exigían un Consejo Técnico Resolutivo. El Consejo de Huelga del Tecnológico (al que se sumaron los institutos de Ciudad Juárez y la Laguna), al pintar muros de edificios públicos y privados, escribieron los nombres de los jóvenes insurgentes ejecutados el 15 de enero. Por ese motivo intervino la policía municipal por primera vez, aprehendiendo algunos estudiantes que fueron liberados horas después. ${ }^{70}$ La toma del Palacio de Gobierno (con autoridades y ciudadanos dentro) por los huelguistas fue la actividad que puso fin al conflicto. El gobernador Flores Sánchez intervino ante la SEP solicitando se aprobara el Consejo Técnico en escasas horas.

La toma de espacios administrativos se repitió en la huelga estudiantil de febrero de 1973, la más prolongada en las instituciones educativas del estado. Alumnos de la Preparatoria Nocturna demandaron la ejecución de los acuerdos de la huelga anterior, además de exigir una reforma académica integral y la destitución del secretario general de la universidad, Sergio Martínez de la Garza, del director de la preparatoria, Enrique Sánchez Silva, ambos acusados de corrupción, así como de los profesores Raúl Medrano y Ernesto Madrid, señalados por los huelguistas como organizadores de grupos paramilitares al interior de la universidad (porros). El edificio de Rectoría fue ocupado por estudiantes de Agronomía y entregado a las autoridades casi un año después. El conflicto se agudizó en escuelas como Agronomía, Ingeniería, Filosofía y Letras, Derecho y la Preparatoria. Estos planteles fueron espacios en donde se experimentó un relevo generacional estudiantil. Los actores de movimientos anteriores se convirtieron en

70 En 1967, el Servicio Secreto de Ciudad Juárez siguió abiertamente la movilización. La Dirección Federal de Seguridad aprehendió de manera selectiva a un estudiante en el contexto de la huelga, y en 1969 retuvo desaparecido al profesor Antonio Becerra Gaytán. Sin embargo, las policías estatales y municipales, muy activas antes de 1967, no intervinieron de nuevo hasta 1972. 
egresados y algunos en catedráticos universitarios, ${ }^{71}$ como Víctor Orozco y Rogelio Luna, ambos secretarios preparatorianos recién destituidos por el impugnado director Sánchez Silva. Profesores y estudiantes huelguistas que militaban o simpatizaban con el CDP, señalados como "agentes extraños" por las autoridades, enfrentados por la policía rural al interior del campus universitario, no se deslindaron de sus militancias políticas. Enunciaron que su lucha por la reforma se debía a lograr el acceso de la clase trabajadora a la universidad.

Aparecieron nuevos actores. Un nuevo aliado para los huelguistas fue el sindicato de trabajadores de la UACH. Otro sector activo y polarizado en dos bandos (oficial y huelguista) irrumpió con fuerza: los padres y madres de familia. De parte de los paterfamilias opuestos se fortalecía la idea de un estudiantado menor de edad, cuya finalidad exclusiva era estudiar y requería protección de influencias radicales. El movimiento, además de librarse al interior de las escuelas, se publicitó día a día por medio de decenas de desplegados. El Consejo Estudiantil de Huelga solicitó al profesor Antonio Becerra Gaytán dialogar con las autoridades universitarias. La mayoría de las escuelas regresó a clases, no así la Preparatoria y Derecho, en donde se sustituyeron maestros y expulsaron alumnos huelguistas. Se perfiló el grupo hegemónico de abogados autonombrado La Mafia, posicionado tras la rectoría y contra la disidencia. El 4 de junio de 1973 inició el Encuentro Nacional de Centros de Estudios Superiores y una Jornada Nacional de Solidaridad con la Universidad de Chihuahua, que inundó de nuevo las calles con apoyo proveniente de otros estados. Como respuesta a la integración de una Comisión Mixta por alumnos y profesores preparatorianos expulsados, uno de sus integrantes fue detenido. El abogado Víctor Orozco fue acusado de intento de homicidio, robo y asociación delictuosa en contra de un chofer de autobús. Permaneció preso dos meses, hasta mediados de octu-

71 Un numeroso grupo redactó y divulgó su postura ante la reforma académica: "La Universidad debe transformarse", donde el punto principal era que la educación superior, subsidiada por la clase trabajadora, debía estar al alcance y sirviendo al pueblo. La educación científica debía beneficiar colectivamente. El Norte, lunes 19 de febrero de 1973, p. 6. 
bre, después de múltiples muestras de solidaridad y la elección del abogado José R. Miller como rector de la universidad.

Entre septiembre y octubre, la recién creada Liga Comunista 23 de Septiembre (a la que ingresaron un número significativo de alumnos tecnológicos de Chihuahua y Ciudad Juárez) secuestró a personajes de la diplomacia y el empresariado en diversas partes del país. El presidente Echeverría se negó a las demandas insurgentes, como el canje de presos políticos. Las policías políticas irrumpieron en múltiples movilizaciones populares tras los militantes clandestinos. El Consejo de Huelga entregó en noviembre las escuelas de Derecho y la Preparatoria, continuando en posesión de Rectoría. Desde el inicio de sus funciones, a Miller Hermosillo se le acusó de cesar y expulsar por venganza a profesores y alumnos huelguistas. Vázquez Mancinas, director de Agronomía (quien junto al abogado Augusto Martínez Gil fueron los únicos directores no opositores a la huelga) fue separado de su cargo sin el procedimiento adecuado, nombrando como director a Víctor Manuel Bravo, quien no era parte del gremio agrónomo.

La tensión en la UACH prosiguió en 1974. Las autoridades universitarias desaparecieron la escuela preparatoria y alentaron el asalto a la escuela de Agronomía. Pablo Martell recuerda que desde la huelga del 67, diversos actores solicitaron que la escuela de Agronomía se trasladara a Delicias. Productores del Distrito 05 ofrecieron 65 mil hectáreas para prácticas, además de la cuenca lechera ${ }^{72}$ y terreno para el plantel. ${ }^{73}$ "Empezamos a meterle fuerte al proyecto de cambiarnos”, recuerda Pablo, quien encontró en Octavio Legarreta un aliado para su reubicación, la cual obedecía a expectativas de formación agropecuaria en espacios adecuados. Sin embargo, debido a la trayectoria política de los agrónomos en movimientos recientes, en enero de 1974 autoridades de Rectoría, en complicidad con una minoría estudiantil opositora a la Sociedad de Alumnos Emiliano Zapata, exhortaron a alumnos de las preparatorias 4 y 10 a ocupar el plantel de Agronomía del campus universitario, que presuntamente funcionaba entonces en Delicias. Alumnos preparatorianos y agrónomos se enfrentaron. Estos

72 El Heraldo. 6 de junio de 1967.

73 El Heraldo. 31 de julio de 1967. 
últimos, junto a la asociación de egresados de la UACH, solicitaron su anexión a la ENA de Chapingo. De nuevo, al ver entorpecido tanto su desarrollo profesional como su participación al interior de la escuela, otra generación de estudiantes y directivos emprendieron acciones para resolver sus agravios inmediatos, iniciando una nueva etapa.

Ante un relevo generacional del estudiantado agrónomo y la elección de futuros inmediatos, Pablo Martell reflexiona críticamente sobre su ausencia en el proyecto iniciado: "lo abandonamos sin darle continuación. Pudimos permanecer como maestros pero no lo hicimos por las múltiples preocupaciones personales de cada uno". Las expectativas de los huelguistas de la ESAHE se modificaron de acuerdo al contexto de sus estudios profesionales y las movilizaciones en que participaron. La Escuela de Agronomía concretizó su expectativa colectiva de acceso a la educación pública, aún con el incumplimiento de ciertas demandas. Sin proponérselo, originaron una serie de estrategias nacionales a su alrededor, fundamentales en la organización estudiantil de 1968. En su calidad de universitarios provenientes de otras regiones, se identificaron con un sector politizado que, mayoritariamente, optó por la movilización popular. Coincidieron temporal y espacialmente con jóvenes que apostaron a derrocar política y violentamente al Estado mexicano, a los que vieron irse sin retorno. Después de su experiencia colectiva, un abanico de posibilidades laborales los regresó a sus lugares de origen o a la ciudad de México, donde se insertaron en proyectos agronómicos institucionales. La escuela de Agronomía perdió su carácter nacional en relación con la planta estudiantil, mayoritariamente local.

Después de un poco menos de cincuenta años, con las trayectorias individuales a sus espaldas, los fundadores regresaron a las aulas de la ahora Facultad de Ciencias Agrícolas y Forestales alrededor de otro proyecto colectivo, para reconocer a una generación que en tiempos desfavorables para la juventud y el campo mexicano estudian producción y administración agropecuaria. Desde su papel fundacional, apelan a construir una memoria conmemorativa que devele el origen de la escuela e incluirla en un calendario del tiempo reciente. Afanados y alegres, intentan 
involucrarse en proyectos académicos. En tiempos presentes de necesaria transformación al interior de las universidades, bajo un nuevo orden mundial neoliberal, me pregunto, ¿qué otro sentido (expectativa, utopía, esperanza) puede generar ese puente entre el pasado y el presente ante el futuro que se asoma para los jóvenes? Desde la arena de la historia, esperaría que los procesos narrados, lejos de convertirse en lecciones nostálgicas, sean retomados en los debates públicos de manera crítica y novedosa para interpretar nuestro mundo, ese que nos tocó vivir y transformar.

\section{BIBLIOGRAFÍA}

Castorena Sáenz, Nithia. Tesis de maestría. Estaban ahí. Las mujeres en los grupos armados de Chihuahua (1965-1973), UACJ, 2013.

Escobar Zerman, Rómulo. Eslabonazos. Relatos y escenas de la vida campirana (1896-1936), 1. ${ }^{a}$ edición, Chihuahua, México, Secretaría de Educación y de Cultura, Gobierno del estado de Chihuahua, 2001.

García Aguirre, Aleida. La revolución que llegaría. México, Memorias subalternas. 2015.

Guevara Niebla, Gilberto. La democracia en la calle: crónica del movimiento estudiantil mexicano. México, IIS, UNAM. 1988.

Koselleck, Rehinart. Futuro pasado. Para una semántica de los tiempos históricos. Madrid, Paidós Ibérica, 1993.

Moreno, Armando. "Ventanas al movimiento estudiantil en la Universidad de Sonora", pp. 313-316, en 154 años de movimientos estudiantiles en Iberoamérica. Coord. González Marín y Sánchez Sáenz. México. UNAM, IIB, Seminario Movimientos Estudiantiles, 2011.

Oikión, Verónica. "El movimiento universitario de 1966 en Michoacán: una historia de confrontación política”, pp. 387-402, en 154 años de movimientos estudiantiles en Iberoamérica. Coord. González Marín y Sánchez Sáenz. México. UNAM, IIB, Seminario Movimientos Estudiantiles, 2011.

Vargas Valdés, Jesús. La patria de la juventud. Los estudiantes del Politécnico en 1968. México, Ediciones Nueva Vizcaya, 2008.

\section{Artículos en internet}


Gómez Nashiki, Antonio. El movimiento estudiantil y la violencia institucional. La universidad michoacana de San Nicolás de Hidalgo, 1956-1966. Disponible en http://www.comie.org.mx/documentos/rmie/v12/n035/pdf/ N35D.pdf

Heredia, Ana Lucía. 1971: el año de los jóvenes regios. Disponible en http:// www.elbarrioantiguo.com/1971-el-ano-de-los-jovenes-regios/

Peláez Ramos, Gerardo. 1967: la huelga estudiantil de las escuelas de agricultura, el Politécnico, las normales rurales y otras instituciones. Disponible en http://www.lahaine.org/b2-img12/pelaez_huel_est.pdf

\section{Fuentes orales}

Entrevista colectiva realizada y transcrita por Alicia de los Ríos Merino a Eduardo Merrem, Pablo Martell, Jorge Posadas y Ricardo Valenzuela los días 23 y 24 de marzo de 2014 en San Luis Potosí.

Comunicaciones con Jesús Vargas Valdés, 2016.

\section{Periódicos}

El Heraldo de Chihuahua. Mayo a septiembre de 1967; julio a noviembre de 1968.

El Fronterizo de Ciudad Juárez, Chihuahua. Mayo a julio de 1967.

El Norte de Chihuahua (consulta realizada por Marco de la Rosa y Lizeth Quintana, entre junio y julio de 2016); mayo a julio de 1967; años 1968, 1972, 1973 у 1974. 